\section{Early medical abortion at home}

Cameron et al. ${ }^{1}$ report on a pilot of early medical abortion in a group of women with pregnancies less than 8 weeks. They demonstrated good patient experiences and high levels of satisfaction in this group of women; in the immediate aftermath of the abortion. I do, however, have serious concerns regarding their administration of mifepristone right away, on the same day, following patient assessment. They acknowledge that "the decision to terminate a pregnancy is not an easy one, and can cause considerable psychological distress for women". Their very approach of administering mifepristone at assessment is likely to cause psychological distress if women are not given enough time to consider their decision; ideally away from the assessment environment. This approach gives an impression of coercion as far as the abortion process is concerned. A minimum of a 24-hour 'cooling off' period is desirable to reduce the risk of psychological distress, and a lot of women would welcome this, as there is evidence that women could be ambivalent about abortions $^{2}$ especially if they are first-time aborters.

As part of their suitability criteria guiding their selection of patients for the study, Cameron et al. included "Certain of decision to have abortion". I do not think that it is possible to assess women and be sure that they are truly certain of their decision to have an abortion there and then; without allowing them some time away from the assessment environment to reappraise their options. It is certainly not an emergency situation and some independent time away from providers of the service is desirable. The Royal College of Obstetricians and Gynaecologists (RCOG) ${ }^{4}$ guidelines on abortion recommends the identification of patients who may require additional support in coming to a decision, providing such support or channelling patients towards such support which may not be available or cannot be provided at the assessment. The guideline considers the interval of between 72 hours and 1 week as an acceptable assessment-to-abortion interval. An attempt to meet the requirements of the guideline in terms of shorter waiting times should not mean breaching the guideline by not allowing any time for patients to fully contemplate the decision and explore all options. It is infinitely better to delay the procedure as advised by the guideline in order that it is thought through and hence reduce the likelihood of psychological distress, than to carry out in haste a procedure that has not been thought through.

It is possible to meet the $\mathrm{RCOG}^{4}$ guidelines for the provision of abortion services by cutting out undue delays. The place to do this is in the referral and appointments procedures, for example, by agreeing referral criteria with local general practitioners (GPs), giving telephone appointments to GPs and accepting faxed referrals rather than posted referrals and appointments. ${ }^{5}$ These are some of the areas where undue delays can be cut out. Not allowing some time from decision making to carrying out the abortion is not the place to try and speed up the process, and may not be serving the best interests of these women. Longer-term follow-up of these women may well reveal psychological morbidity.

Umo Ita Esen, LLM, FRCOG

Consultant, Department of Obstetrics and Gynaecology, South Tyneside NHS Foundation Trust, South Shields, Tyne and Wear, UK; umo.esen@ stft.nhs.uk

Competing interests None.

J Fam Plann Reprod Health Care 2011;37:123. doi:10.1136/jprhc.2011.0071

\section{REFERENCES}

1 Cameron S, Glasier A, Dewart H, et al. Women's experiences of the final stage of early medical abortion at home: results of a pilot survey. J Fam Plann Reprod Health Care 2010;36:213-216.

2 Husfeldt C, Hansen SK, Lyngberg A, et al. Ambivalence among women applying for abortion. Acta Obstet Gynecol Scand 1995;74:813-817.

3 Holmgren $\mathbf{K}$. Women's evaluation of three early abortion methods. Acta Obstet Gynecol Scand 1992;71:616-623.

4 Esen U, Koram K, Doherty E, et al. Termination of pregnancy in South Tyneside. J Obstet Gynaecol 2006;26:791-794.

5 Royal College of Obstetricians and Gynaecologists. The Care of Women Requesting Induced Abortion (Evidence-based Clinical Guideline Number 7). 2004. http:// www.rcog.org.uk/womens-health/clinicalguidance/care-womenrequesting-inducedabortion [accessed 16 November 2010]. 